\title{
Nasal Mask: An Alternative to Prevent Contagion during Essential Activities
}

\author{
Ana María González Farías ${ }^{1 \#, ~ M o n i c a ~ S i e r r a ~ M a r t i ́ n e z ~}{ }^{1 \#, ~ A l m a ~ R o s a ~ S a ́ n c h e z-C o n e j o ~}{ }^{3}$, Thalía \\ Fernanda Camarillo González ${ }^{2}$, Valeria Juárez García ${ }^{2}$ and Gustavo Acosta-Altamirano ${ }^{4,5 *}$ \\ ${ }^{1}$ Unidad de Investigación, Hospital Juárez de México, México
}

${ }^{2}$ Facultad de Estudios Superiores Zaragoza, Universidad Nacional Autónoma de México, México

${ }^{3}$ Dirección General Hospital Regional de Alta Especialidad Ixtapaluca, México

${ }^{4}$ Dirección de Investigación Hospital Regional de Alta Especialidad Ixtapaluca, México

${ }^{5}$ Escuela Superior de Medicina, Instituto Politécnico Nacional, Mexico

${ }^{\#}$ Both authors are equally contributed

*Corresponding author: Gustavo Acosta-Altamirano, Director de Planeación, Enseñanza e Investigación del Hospital Regional de Alta Especialidad de Ixtapaluca, Estado de México, Carretera México-Puebla $34.5 \mathrm{~km}$. Pueblo de Zoquiapan, Ixtapaluca Edo CP 56530, Mexico

\section{ARTICLE INFO}

Received: March 17, 2021

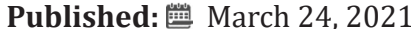

Citation: Ana María GF, Monica Sierra M, AR Sánchez-Conejo, Thalía Fernanda Camarillo G, Valeria Juárez G, G Acosta-Altamirano. Nasal Mask: An Alternative to Prevent Contagion during Essential Activities. Biomed J Sci \& Tech Res 34(4)-2021. BJSTR. MS.ID.005595.

Abbreviations: CNS: Central Nervous System; ARDS: Acute Respiratory Distress Syndrome; CSF: Cerebrospinal Fluid; ACE2: Angiotensin-Converting Enzyme 2; TMPRSS2: Transmembrane Protease Serine 2

\section{ABSTRACT}

Introduction: One of the main routes of transmission of SARS-CoV-2 is through the nostrils. The virus binds to the ACE2 cellular receptor facilitating its spread to the Central Nervous System (CNS), whose affectation can cause epilepsy, encephalitis, and acute respiratory distress syndrome (ARDS). The nasal mask is a protective barrier that allows the correct filtration of inhaled and exhaled air, preventing the entry of various respiratory microorganisms.

Material and Methods: The prototyping materials were polypropylene fabric (100\%) Spunbond-Meltblown-Spunbond, commonly known as SMS, which is a hypoallergenic, breathable, tri-laminate fabric that has a particle capture efficiency of $0.3 \mu \mathrm{m}$. SMS also allows adequate ventilation and is water-repellent, so it blocks the passage of pathogenic microorganisms from bodily fluids through the fabric, providing an efficiency greater than $99 \%$.

Results and Discussion: The nasal mask will not displace the face mask. On the contrary, it will be an additional protective measure in daily activities where the conventional face mask has to be removed, reducing SARS-CoV-2 infections, and preventing the virus from spreading to the CNS. The final prototype adapts appropriately to the face, allowing adequate air filtration, and it does not affect the palatability of food. It can be used under the face mask, providing comfort, double protection, and easy access when removing the face mask and leaving the mouth uncovered.

Conclusion: The nasal mask is an alternative for patients treated in dental offices, diners in restaurants when actively eating or drinking, and long-duration flight passengers eating meals. The nasal mask will allow the economic reactivation of these productive activities while reducing the risk of contagion.

\section{Short Communication}

Mexico ranks third in COVID-19 worldwide mortality [1]. After a year of the onset of the first cases, one of the main concerns of this global pandemic is to mitigate contagion. The CDC recently issued a statement requesting the use of double face masks to prevent the spread of the new B 1.1.7 variants, which have a $75 \%$ higher transmissibility than variants $501 . Y 2$ and P.1 [2,3]. SARSCoV-2 is transmitted through droplet particles ( $>5$ to $10 \mu \mathrm{m}$ ) or aerosols $(\leq 5 \mu \mathrm{m})$. These particles are released when an infected 
person coughs, sneezes, or speaks [4]. Most of these particles fall at a distance less than one meter from the emitter. However, if they are forcefully ejected, they can travel more than two meters. SARSCoV-2 has four structural proteins: Spike (S-protein), Nucleocapsid (N-protein), Membrane (M-protein), and Envelope (E-protein). For the virus to infect the host cell, the S-protein must bind to the angiotensin-converting enzyme 2 (ACE2) receptor. This binding triggers a structural change in the S-protein, allowing further binding to the cell membrane to release its genetic material into the cytoplasm and start the viral replication cycle $[5,6]$. The virus transmission can occur through three different routes: ocular, nasal, and oral (Figure 1). One of the main routes of infection occurs through the nasal cavity, which contains three types of epithelia: scaly, respiratory, and olfactory. Olfactory epithelium cells express the highest levels of ACE2 proteases and transmembrane protease, serine 2 (TMPRSS2), necessary for infection [6].

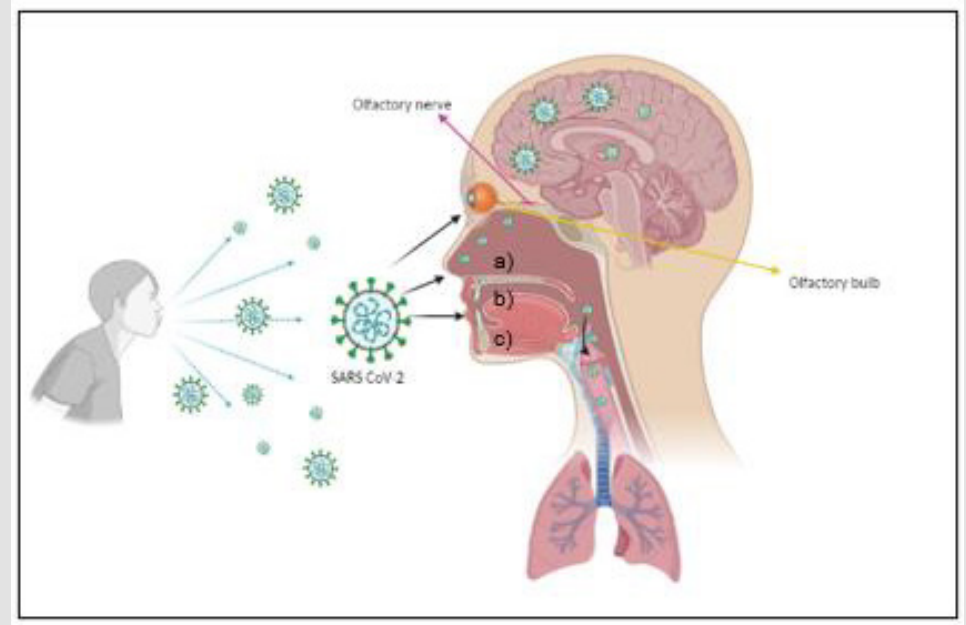

Figure 1: Transmission of SARS-CoV-2 via:

a) Conjunctiva,

b) Nostrils,

c) Mouth, and its entry into the CNS through olfactory nerve endings, binding to ACE2 receptors. Designed with BioRender. com.

Once the virus is inside the olfactory epithelium cells, it spreads to the olfactory bulb, passing through the cribriform plate and reaching the meninges and cerebrospinal fluid (CSF), which serves as a vehicle for its spread into the central nervous system (CNS). SARS-CoV-2 has already been detected in this tissue [6]. Through the nerve and the olfactory bulb, the virus travels using a transsynaptic pathway. It can reach the brain stem, affecting the respiratory center, leading to acute respiratory distress syndrome (ARDS), which is the leading cause of death in patients with Covid-19 [6,7]. In addition to infection through the olfactory nerve and CSF, SARS-CoV-2 can access the CNS by hematogenous dissemination because it infects endothelial cells in blood vessels reaching any organ [8]. On the other hand, the conjunctiva is a site of direct inoculation. Infected secretions and tears are transported through the nasolacrimal duct and drained into the nasopharynx, leading to lower respiratory tract infection [9]. Considering the SARS-CoV-2 spreading mechanisms, global organizations have implemented effective protective measures. Mandatory use of face masks has been implemented for all people 2 years of age and older. Masks must be worn in public places and transport of any kind covering the nose, mouth and secured under the chin [10].

Various types of face masks have been designed, for instance, N95s with three structural layers and KN95s that consist of four layers. Both types retain particles up to 0.3 microns with $95 \%$ efficiency, so they are recommended for healthcare personnel [4]. Even though face masks protect the oral and nasal pathways, there are daily activities, such as eating or drinking, that force the masks to be removed in public or crowded places, leaving exposed two of the three routes of transmission of the virus (Figure 2). In an effort to reduce the high impact of SARS-CoV-2 infection, this work aims to design a nasal mask that fits any person's nose regardless of their physiognomy or age, allowing a proper filtration of the inhaled and exhaled air, reducing the risk of contagion of different respiratory microorganisms, including the SARS-CoV-2 virus, whenever the face mask has to be removed. 


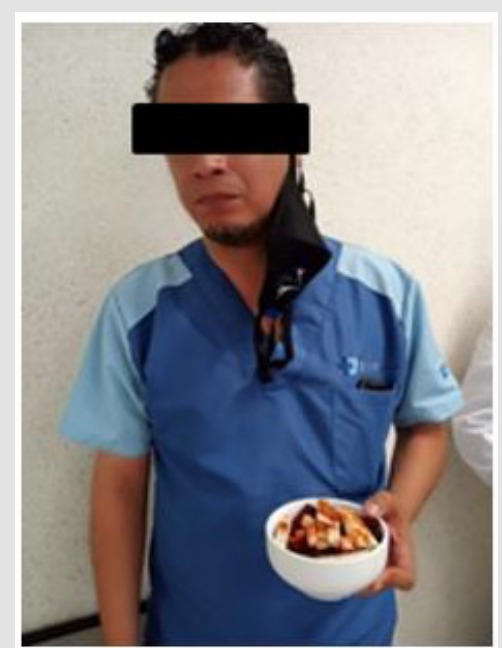

Figure 2: Staff removing the face mask to eat.

\section{Material and Methods}

Different prototypes were developed using various materials such as natural fibers (cotton, abaca, coir, hemp, flax, ramie, sisal, among others), animal origin textile fibers (such as alpaca, angora, wool), synthetic polymers, or non-woven materials (nylon, polyester, acrylic or polyolefin fibers), multilayer and disposable fabric. The design considered the size of aerosols and the route of infection of the virus to ensure adequate protection and breathing. It was determined that synthetic non-woven polypropylene fabric consisting of three layers, Spunbond-Meltblown-Spunbond (SMS), had a particle capture efficiency of $0.3 \mu \mathrm{m}$ and prevented particles from entering the inner layer (Meltblown). This hypoallergenic, breathable, air-permeable material has a high filtration efficiency. It is water-repellent, so it can effectively block the passage of pathogenic microorganisms from fluids through the fabric, providing an efficiency higher than $99 \%[11,12]$. The measurements of the prototypes were determined based on the age group, gender, and facial physiognomy of different people, considering various anatomical points (length: from root to tip, height: from the midpoint of the root to the sub nasal point, width: the distance between the alas of the nose, and depth: from the sub nasal point to the tip). Based on the landmarks, five polygonal prototypes adaptable to the nose and nasal bridge were designed in different sizes, providing a correct sealing.

\section{Results}

The nasal protector consisted of the body

1) Folding nasal clip

2) Placed on the upper body, a fold

3) Placed at the bottom part of the body, and

4) A set of clamping bands (Figure 3).
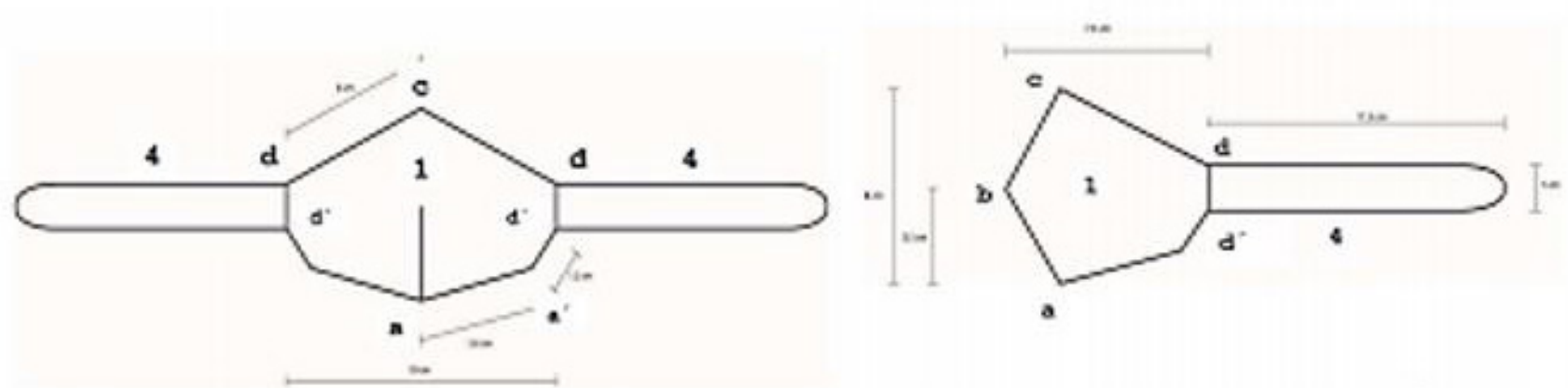

Figure 3:

a) Nasal mask front view

b) Side view

Designed by Adriana Ramos González. 


\section{Body}

a-a': $5.6 \mathrm{~cm} \quad$ a-d: $1.2 \mathrm{~cm}$

d-d': $10 \mathrm{~cm}$

Material Used: Synthetic polypropylene tri-laminate fabric (Spunbond-Meltblown-Spunbond). Water-repellent, breathable, polygonal shaped with the following measures, considering the reference points (Figure 4):

$\begin{array}{ll}\text { a-b: } 3.5 \mathrm{~cm} & \text { c-d: } 6 \mathrm{~cm} \\ \text { a-c: } 8 \mathrm{~cm} & \text { b-d: } 7.3 \mathrm{~cm}\end{array}$

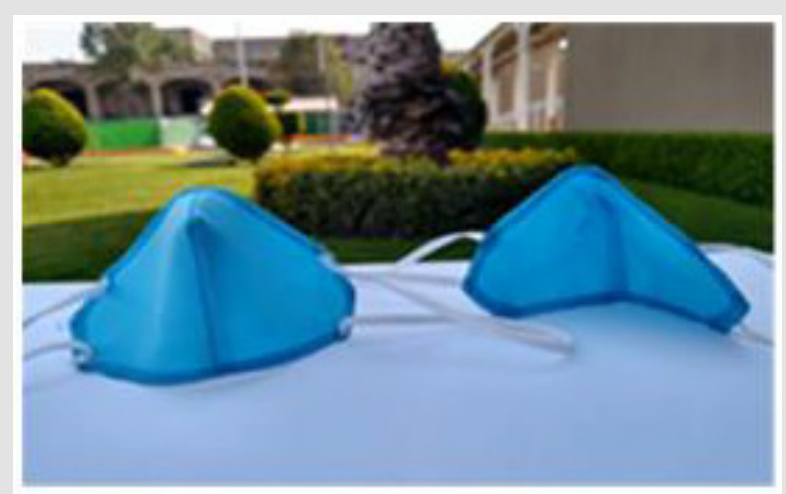

Figure 4: Final prototype of nasal mask.

\section{Adjustable Nasal Strap}

Made of any suitable material, preferably aluminum. When used, it can be folded in the direction of the nose and adjusted to its shape, reinforcing the body's sealing.

\section{Fold}

Allows the correct fit to the nose's shape and the passage of air for breathing.

\section{Clamping Bands}

They are located in pairs at each end side of the body. They can be worn on the ears, but they can also be tied behind the head to fix the body. They can be elastic and adjustable, made of any material that ensures correct gripping and facial sealing, avoiding leaks around the nose. Length: $11.5 \mathrm{~cm}$, separation between parallel lines: $1 \mathrm{~cm}$. The nasal mask's final structure allows the air to pass from the interior space of the protector to the outer space of the same and vice versa, retaining any particles or sprinkling dispersed in the air that may contain an infectious or polluting agent (Figure 4).

\section{Discussion}

The use of the nasal masks aims to keep the nose protected, which prevents the virus from entering and easily invading the CNS through the bulb and olfactory nerve, causing neurological alterations, such as strokes, epilepsy, and encephalitis, which have already been documented [6]. The nasal mask does not intend to displace face masks, nor will it prevent the disease. The nasal mask should also be used in combination with other barrier devices, such as face shields, conventional face masks, lenses, or googles to provide double protection. When the oral cavity is needed free to eat, drink or receive Stomatological treatment, the nose will be protected, and thus the virus will not enter through this route. Besides, its use does not interfere with the palatability of food and allows adequate ventilation when used alone or in combination with other protective barriers. The nasal mask is a protective measure that benefits the entire population, including patients with comorbidities (systemic hypertension, diabetes, obesity) and older adults, who are more prone to suffer complications from COVID-19 due to their risk factors.

\section{Conclusion}

The nasal mask is a device whose function is to prevent the entry of infectious microorganisms. It is also a protective measure that reduces the risk of contagion for patients who go to dental offices, people dining in restaurants when actively eating or drinking, and passengers eating meals during long-duration flights, among others. This nasal mask will allow to reactivate the economy and perform any productive activity. It is essential to mention that it is not intended to displace the face mask. As with any other mask, for its proper use, it is crucial to perform a correct hand washing, check the material integrity, avoid touching it during use, and store it in a plastic bag after removing it. The amount of time a mask can be used will depend on the type of constituent materials.

\section{References}

1. (2020) WHO Coronavirus Disease (COVID-19) Dashboard | WHO Coronavirus Disease (COVID-19) Dashboard.

2. Greaney AJ, Loes AN, Crawford KHD, Starr TN, Malone KD, et al. (2021) Comprehensive mapping of mutations in the SARS-CoV-2 receptorbinding domain that affect recognition by polyclonal human plasma antibodies. Cell Host Microbe 29(3): 463-476.e6.

3. Leung K, Shum MHH, Leung GM, Lam TTY, Wu JT (2020) Early transmissibility assessment of the N501Y mutant strains of SARS-CoV-2 in the United Kingdom, October to November 2020. Eurosurveillance 26(1): 2002106 
4. Yim W, Cheng D, Patel SH, Kou R, Meng YS, et al. (2020) KN95 and N95 Respirators Retain Filtration Efficiency despite a Loss of Dipole Charge during Decontamination. ACS Appl Mater Interfaces 12(49): 5447354480 .

5. Acosta Altamirano G (2020) Estrategias del HRAEI ante el reto de COVID-19. Hospital Regional de Alta Especialidad Ixtapaluca. Liderazgo y Experiencia Médica.

6. Butowt R, Bilinska K (2020) SARS-CoV-2: Olfaction, Brain Infection, and the Urgent Need for Clinical Samples Allowing Earlier Virus Detection. ACS chemical neuroscience 11(9): 1200-1203.

7. Machado C, DeFina PA, Chinchilla M, Machado Y, Machado Y (2020) Brainstem dysfunction in SARS-COV-2 infection can be a potential cause of respiratory distress [Internet]. Neurology India 68(5): 989-993.

8. Torres Estrella CU, Sierra M, Chávez Martínez MA, García Salazar E Acosta G (2020) Plasma Exchange as A Therapeutic Alternative to

\section{ISSN: 2574-1241}

DOI: $10.26717 /$ BJSTR.2021.34.005595

Gustavo Acosta-Altamirano. Biomed J Sci \& Tech Res

(C) This work is licensed under Creative

Submission Link: https://biomedres.us/submit-manuscript.php
Eliminate Viral RNA and Macromolecules Involved in The Immune Response of Patients with Sars-Cov-2. Biomed J Sci \& Tech Res 29(1): 2020.

9. Ho D, Low R, Tong L, Gupta V, Veeraraghavan A, et al. (2020) COVID-19 and the Ocular Surface: A Review of Transmission and Manifestations. Ocular Immunology, and Inflammation 28(5): 726-734.

10. (2021) How to Protect Yourself \& Others. Centers for Disease Control and Prevention.

11. Tessarolo F, Nollo G, Maniglio D, Rigoni M, Benedetti L, et al. (2021). Testing Surgical Face Masks in an Emergency Context: The Experience of Italian Laboratories during the COVID-19 Pandemic Crisis. International Journal of Environmental Research and Public Health 18(4): 1462.

12. Walawalkar S, Joshi M, Khattry N, Sapra BK, Khan A, et al. (2020) Particle removal from air by face masks made from Sterilization Wraps: Effectiveness and Reusability. PLoS ONE 15(10): e0240398.

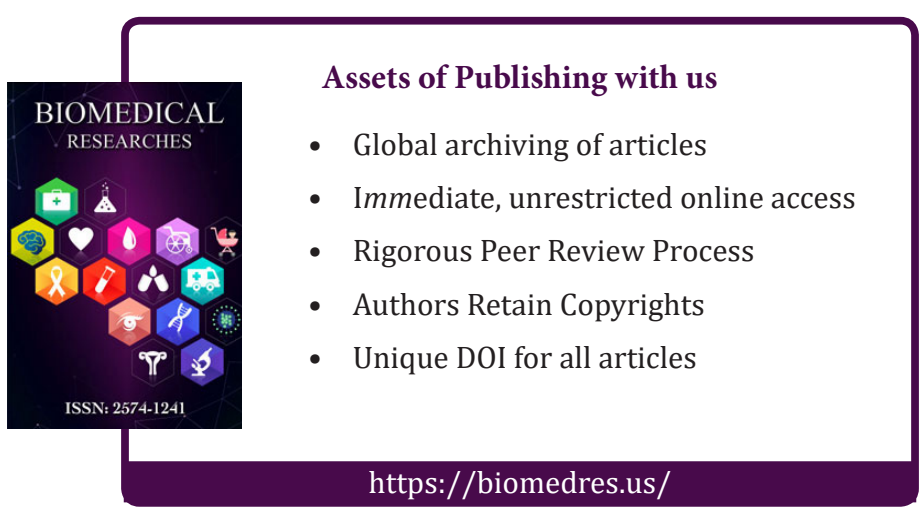

